How Locomotion Concerns Influence Perceptual Judgments, Scholer, A. A., Eitam, B., Stadler, G., \& Higgins, E. T. (C) 2017. Copyright Guilford Press. Reprinted with permission of The Guilford Press

Word Count: 6164

MS\#: 16-079R

Research Article

How Locomotion Concerns Influence Perceptual Judgments

\author{
Abigail A. Scholer \\ University of Waterloo \\ Baruch Eitam \\ University of Haifa \\ Gertraud Stadler \\ University of Aberdeen \\ E. Tory Higgins \\ Columbia University
}

Author note: Abigail A. Scholer, Department of Psychology, University of Waterloo; Baruch Eitam, Department of Psychology, University of Haifa; Gertraud Stadler, Institute of Applied Health Sciences, University of Aberdeen; E. Tory Higgins, Department of Psychology, Columbia University. This research was supported in part by a grant from the Social Sciences and Humanities Research Council to Abigail Scholer.

Correspondence concerning this article should be addressed to Abigail Scholer, Department of Psychology, University of Waterloo, Waterloo, ON, Canada, ascholer@uwaterloo.ca. 


\title{
LOCOMOTION AND PERCEPTION
}

\begin{abstract}
Successful self-regulation involves both assessment (e.g., making the right choices) and locomotion (e.g., managing change and movement). Regulatory mode theory is a motivational framework that highlights the ways in which these locomotion versus assessment concerns can receive differential emphasis across both individuals and situations. Although we know that locomotion motivation modulates goal-related movement, it is unclear whether these rather high-level concerns influence perceptual judgments of physical movement. Four studies investigated whether locomotion motivation also increases individuals' perceptual judgments of movement. Across studies, whether locomotion motivation was measured (Studies 1a and 1b) or manipulated (Studies 2 and 3), individuals high in locomotion motivation judged more movement in static images relative to individuals chronically low in locomotion (Study 1a and $1 \mathrm{~b}$ ) and to individuals in an assessment motivational state (Studies 2 and 3). Implications for understanding the nature of locomotion motivation, and motivated perceptual judgments more generally, are discussed.

Keywords: regulatory mode, locomotion, assessment, movement, perception, selfregulation
\end{abstract}




\section{LOCOMOTION AND PERCEPTION}

Successful self-regulation involves both choosing the ends and means of goal pursuit (assessing) and then actually pursuing the goal (locomoting; Carver \& Scheier, 1998; Gollwitzer, 1990; Miller, Galanter, \& Pribram, 1960). Not surprisingly, distinguishing between these two critical tasks has been a hallmark of many models in self-regulation, in particular stage models that differentiate between an initial deliberation stage followed by a goal pursuit stage (e.g., Gollwitzer, 1990). Although stage models suggest that these two tasks are both interdependent and sequential (i.e., individuals assess in order to locomote), recent research provides evidence that individuals and situations can also differ in the extent to which they emphasize self-regulatory concerns with establishing what is the right choice (assessment) versus managing change and movement from state to state (locomotion) (Higgins, Kruglanski, \& Pierro, 2003; Kruglanski et al., 2000). In the current studies, we examine whether and how these locomotion concerns with psychological change and movement within goal pursuit may influence perceptual judgments. Specifically, we test the idea that locomotion motivation is not only about being motivated to change and move but also about being more likely to judge that movement has occurred in the world - a motivated perceptual judgment effect.

\section{Motivation and Perceptual Judgments}

Theorizing and evidence suggests that active goals and values influence perceptual representations, presumably even at very early stages of perception (e.g., Balcetis \& Dunning, 2010, 2006; Balcetis, Dunning, \& Granot, 2012; Bruner \& Postman, 1949; Riccio, Cole, \& Balcetis, 2013). Active goals influence perceptual judgments and perception in ways that facilitate goal fulfillment: participants are more likely to see ambiguous figures in ways that promote positive, not negative, personal outcomes 


\section{LOCOMOTION AND PERCEPTION}

(Balcetis \& Dunning, 2006) and perceive distances as shorter when they know they will have to traverse them in socially uncomfortable ways (Balcetis \& Dunning, 2007). Valued objects and goal-relevant objects (whether positive or negative) are seen as closer (Balcetis \& Dunning, 2010; Xiao \& Van Bavel, 2012) and achieve perceptual dominance in a binocular rivalry task (Balcetis et al., 2012), whereas even highly salient but goal irrelevant stimuli are often missed (Bruner \& Postman, 1949; Eitam, Yeshurun, \& Hassan, 2013).

This work suggests that people are likely to see the world around them in ways that facilitate their active and valued goals. The mountain is less steep when people are at the bottom versus at the top; the food is closer when people are hungry versus not. In the absence of clear goal facilitation, however, it is not well understood if fundamental motivations will influence perceptual judgments. Thus, rather than examining whether a discrete, proximal goal influences perception, the current studies examine whether a general motivational concern influences perceptual judgments.

Under conditions in which situational signals are weak versus strong, an individual's chronically or temporarily accessible constructs may be particularly likely to influence the "blips of meaning" that individuals extract from situational input (Kelly, 1955, p. 145; see also Higgins, 1996; Higgins, King, \& Mavin, 1982; Higgins \& Scholer, 2008; McClelland \& Atkinson, 1948). Indeed, research in cultural psychology supports the idea that broad cultural differences influence the ways in which people attend to and parse their environments (e.g., Masuda \& Nisbett, 2001). We propose that differences in fundamental motivational orientations - specifically, locomotion motivation - also have the potential to shape in quite general ways how people make perceptual judgments about 


\section{LOCOMOTION AND PERCEPTION}

the world. Specifically, we test whether locomotion motivation leads individuals to be more likely to make judgments of movement - a perceptual feature that is likely to be modulated by experience and expectations (e.g., Allport \& Pettigrew, 1957; Whiteside, 1963; but see Gibson, 1954).

\section{Locomotion Motivation}

Regulatory mode theory distinguishes between two motivational functions, locomotion and assessment, highlighting the ways in which these functions can operate independently (Higgins et al., 2003; Kruglanski et al., 2000). The assessment function is concerned with establishing what is the right thing to do through critical evaluation and comparisons of options; "should I choose goal X or goal Y?", "should I implement my plan in this way or that way?" Assessment, whether measured or manipulated, is associated with prioritizing full evaluation and comparison of the alternative options (Avnet \& Higgins, 2003) and desiring to do what is right (Appelt, Zou, \& Higgins, 2010), even if that means delaying action (Scholer \& Higgins, 2012).

In contrast, the locomotion function is concerned with managing movement from state to state, with effecting change. Locomotion, whether measured or manipulated, is associated with valuing action over inaction (Avnet \& Higgins, 2003; Scholer \& Higgins, 2012), even if the action is impulsive (Mannetti et al., 2009) or does not clearly advance one’s goals (Higgins et al., 2003).

Recent work provides support for the idea that when individuals are in a locomotion state, movement and change are highly valued. Individuals in a locomotion orientation are more persuaded by advertisements that use dynamic, not static images (Mannetti, Giacomantonio, Higgins, Pierro, \& Kruglanski, 2010) and report change in 


\section{LOCOMOTION AND PERCEPTION}

general as valuable (Scholer \& Higgins, 2012). Furthermore, individuals high in locomotion motivation not only value mental movement, but are actually more active (i.e., take more steps each day) than individuals low in locomotion motivation (Stadler, Eitam, Scholer, \& Higgins, 2016).

We propose that the value placed on movement and change that is generated by the locomotion system may motivate not only movement-related goal pursuit processes, but may also influence perceptual judgments of movement in the world, especially in ambiguous or vague stimuli (Higgins, 1996; Higgins \& Scholer, 2008). While the primary goal of the current paper is to establish whether there is a link between locomotion and perceptual judgments of movement, we also tested one possible mechanism — increased activation of the motor system — in one study. To preview our findings, the proposed link between locomotion and perceptual judgments of movement received support; however, we did not find evidence to support the mechanism of increased activation of the motor system. Below we introduce the rationale for testing this particular mechanism, and in the General Discussion this mechanism, as well as other possible mechanisms, are discussed in light of our findings.

\section{Motor Resonance Hypothesis}

One unique route through which locomotion motivation could influence perception - increased activation of the motor system — was tested in Study 3. There were a number of reasons that it was plausible to test this mechanism, which we label the motor resonance hypothesis. Stronger locomotion motivation is associated with substantially more physical locomotion as measured by a pedometer (Stadler et al., 2016), which may suggest that locomotors have a higher tonic (or "baseline") activity in 


\section{LOCOMOTION AND PERCEPTION}

areas related to motor movement. Second, multiple experiments driven by the discovery of 'mirror neurons' in monkeys (di Pellegrino, Fadiga, Fogassi, Gallese, \& Rizzolatti, 1992; Gallese, Fadiga, Fogassi, \& Rizzolatti, 1996) as well as by other frameworks (Theory of Event Coding; Hommel, 2009; Hommel, Müsseler, Aschersleben, \& Prinz, 2001a), have demonstrated that the perception (judgment) of one's own as well as other's movements is associated with activation in relevant motor brain regions/"motor codes" (for a recent example see Orgs et al., 2016). Taken together, it is possible that if the motor regions of individuals with stronger locomotion concerns are more active, they would be more likely to produce perceptual judgments of increased movement. ${ }^{1}$

\section{Overview of Studies}

Building on work on motivation and perceptual judgments, the goal of this paper is to conduct an initial foray into whether locomotion motivation leads to increased judgments of movement. If detected, this relation may have important implications for goal engagement. For instance, it may explain prior work showing that locomotors are more engaged by dynamic versus static images (Mannetti et al., 2010). Specifically, it is possible that increased perceptual judgments of movement are making the environments more engaging in the eyes of locomotors (Higgins, 2000, 2006). In other words, if individuals in a locomotion state do have increased perceptual judgments of movement in the world, this may be one of the ways in which they keep their eyes focused on the prize (Kruglanski et al., 2000). It may contribute to their ability to move on and put past wrongs behind them (Pierro et al., 2008). It may make deadlines feel closer, leading to

\footnotetext{
${ }^{1}$ One may think that this hypothetical mechanism is not related to motivation. However, evidence from our lab (Mark \& Eitam, 2016) shows that 'automatic imitation,' hypothesized to rest on the same mechanisms described above, disappears completely when the movements are (task) irrelevant. Hence motivational relevance may play a key role in modulating these seemingly passive effects.
} 
LOCOMOTION AND PERCEPTION

less procrastination (Pierro, Giacomantonio, Pica, Kruglanski, \& Higgins, 2011). Such implications are further explored in the General Discussion.

Four studies tested the prediction that locomotion motivation is associated with increased perceptual judgments of movement, using both a chronic measure of locomotion (Study 1a and 1b) and a state induction (Studies 2 and 3). Study 3 built on the earlier studies to explore one potential mechanism of the effect (the motor resonance hypothesis): whether a marker of motor activation (performance on a go/no-go task) would serve as a mediator of the locomotion-induced change in movement perceptual judgments.

\section{Study 1a}

\section{Method}

Participants. Undergraduate students (86, 48 females) at a small liberal arts college in the United States completed this study for credit or payment. The goal was to collect data from as many participants as possible during the semester; given the small subject pool we knew the sample would not exceed 100 participants.

Materials and Procedure. A few weeks prior to coming into the lab, participants completed the 24-item regulatory mode scale (Kruglanski et al., 2000) online as part of a battery of questionnaires unrelated to the current study. Participants indicated their agreement with statements reflecting both locomotion and assessment on a scale from 1 (strongly disagree) to 6 (strongly agree). Assessment was measured with 12 items such as "I often compare myself with other people" and "I like evaluating other people's plans." Locomotion was measured with 12 items such as "I am a doer" and "When I decide to do something, I can't wait to get started.' The two scales showed a small but 


\section{LOCOMOTION AND PERCEPTION}

nonsignificant correlation, $r=.15, p=.15$, consistent with earlier findings. Both scales showed satisfactory reliability as in earlier research (Cronbach's $\alpha=.74$ for locomotion, $\alpha$ $=.81$ for assessment).

In the lab session, participants first completed a number of tasks unrelated to the current study. ${ }^{2}$ At the end of the experimental session, participants were asked to view a series of four pictures and rate how much movement they saw in the pictures across six items adapted from Mannetti et al. (2010). Specifically, participants were told, "In this pilot study, you will be asked to make ratings about a series of pictures. There are no right or wrong answers. We are simply interested in how people evaluate these pictures. This info will help us decide what images to use in a future study."

For each picture, participants were asked how much of a movement-related attribute was represented in the picture on a scale ranging from 1 (none) to 7 (a lot) for 6 attributes (movement, energy, change, stability, stillness, and slowness, with the last 3 reverse-scored). All pictures contained a solitary target running or walking against a different background (see Appendix A for pictures).

\section{Results and Discussion}

To create an index of perceived movement, movement ratings were averaged across all four pictures $(\alpha=.72)$. This movement index was then simultaneously regressed on locomotion and assessment. The mean rating on the movement index was 4.64 (SD $=.52$ ). As predicted, participants higher in locomotion reported more movement (for each additional point in locomotion they perceived $b=.23$ more movement, $S E=.10,95 \% C I$ :

\footnotetext{
${ }^{2}$ Because the participant pool at this small college was very limited in size, participants were often asked to complete multiple unrelated studies during a single session.
} 
LOCOMOTION AND PERCEPTION

$[.02, .43], t(84)=2.20, p=.03) .{ }^{3}$ There was no significant relationship between assessment and movement judgments, $b=-.012, S E=.08, C I:[-.17, .14], t(84)<1, p=.88$. This study provided preliminary evidence that locomotion motivation may affect perceptual judgments. Notably, this relationship was observed even when locomotion motivation was assessed weeks before the experimental session. It is interesting to note that the perceptual judgment was not negatively correlated with assessment motivation $(r=.009$, $p=.93$ ), providing further support for the independence of the two motivational systems.

\section{Study 1b}

Given the constraints for our sample size in Study 1a, Study 1b was designed to replicate Study 1a using a large online sample. By collecting the data on Amazon's Mechanical Turk, we were also able to examine if the effect would replicate in a community sample.

\section{Method}

Participants. Participants $(668,296$ females, 354 males, 2 other, 16 did not report gender, $M_{\text {age }}=25.67$ years, $S D=10.94$ ) completed this short online study on Amazon's Mechanical Turk for US\$0.75. Sample size was determined by sensitivity. Specifically, given our previous studies, we wanted the study to be sensitive enough to differentiate between a lack of an effect and a beta coefficient of $\sim .20$ for regressing the perception of movement on locomotion score. As such we ran the study until the width of the $95 \%$ confidence interval (using 'attentive' participants only, see below for more detail) was

${ }^{3}$ This result was replicated in a study using an Israeli Hebrew speaking sample $(N=50)$ with a Hebrew translation of the locomotion scale instrument. In this sample also, as locomotion increased, perception of movement increased, $b=.25$ ( $\mathrm{se}=.12,95 \% \mathrm{CI}$ : .02, $.49), t(47)=2.15, p=.04$. 


\section{LOCOMOTION AND PERCEPTION}

smaller than this value (Dienes, 2008). This stopping rule ensures that if 0 is included in the confidence interval, interesting effects values $(b=\sim .2)$ will not. We also ran a Bayesian regression on the final results. Given an institutional requirement that Mechanical Turk participants be allowed to click through a study and still receive credit, our final sample size for participants who completed both the regulatory mode and picture rating task was 668 .

Materials and Procedure. Participants first completed a few individual difference measures, including the 24-item regulatory mode scale (Kruglanski et al., 2000) used in Study 1a. The other measures were included to minimize the likelihood that participants could determine our specific study hypotheses. There was no significant correlation between the two scales $(r=.04, p=.36)$, consistent with earlier findings. Both scales showed satisfactory reliability as in earlier research (Cronbach's $\alpha=.88$ for locomotion, $\alpha=.85$ for assessment). Participants were then asked to complete the same picture rating task used in Study 1 a.

At the end of the study and prior to completing demographic information, participants were asked to complete an attention check measure (Oppenheimer, Meyvis, \& Davidenko, 2009). Specifically, participants were presented with a multiple choice question ("We are also interested in how carefully people pay attention to instructions. Please select the "none of the above" option below) and five options (I am completing this on a desktop computer, I am completing this on a laptop, I am completing this on a mobile phone, I am completing this on a tablet, none of the above"). We included this as an a priori exclusion criterion; we report results below including all participants and 
LOCOMOTION AND PERCEPTION

including only participants who passed this attention check by selecting "None of the above" (92\%).

\section{Results and Discussion}

To create an index of perceived movement, movement ratings were averaged across all four pictures $(\alpha=.80)$. This movement index was then simultaneously regressed on locomotion and assessment. The mean rating on the movement index was 4.58 (SD $=.82)$.

The pattern of results was the same whether or not we excluded participants who failed the attention check. As predicted and replicating Study 1a, participants higher in locomotion reported more movement (full sample: $b=.11, S E=.04,95 \% C I:[.03, .19]$, $t(665)=2.76, p=.006$; including only those who passed attention check: $b=.12, S E=.04$, $95 \%$ CI: $[.04, .20], t(609)=2.94, p=.003)$. There was no significant relationship between assessment and judged movement (full sample: $b=.07, S E=.04,95 \% C I:[-.007, .14]$, $t(665)=1.77, p=.08$; including only those who passed attention check: $b=.05, S E=.04$, $95 \% C I:[-.007, .14], t(609)=1.38, p=.17)$. Using a large sample, this study provided further evidence that locomotion motivation may affect perceptual judgments.

In addition, using JASP (Love et al., 2015) we ran a Bayesian regression using the above model (Morey \& Rouder, 2015; Rouder, Morey, Speckman, \& Province, 2012). As can be seen in Table 1, this analysis lends substantial support for the effect of locomotion (Bayes factor $=6.347$; compared to the null model) on perceptual judgments of movement and substantial support for the lack of a similar effect of assessment (Bayes factor $=.252 ;$ compared to the null model).

\section{Study 2}




\section{LOCOMOTION AND PERCEPTION}

While Studies 1a and $1 \mathrm{~b}$ provided preliminary evidence that locomotion was related to the perception of movement in ambiguous stimuli, the observational nature of the studies meant that the direction of causality could not be established (e.g., it is possible that people who see more movement in the world try to "keep up" with these perceptions and hence are high on locomotion). Study 2 was designed to directly test the idea that increased locomotion motivation leads to increased perceptual judgments of movement by manipulating locomotion and assessment.

We employed a standard manipulation of regulatory mode that has been used successfully in many studies (e.g., Avnet \& Higgins, 2003; Orehek, Mauro, Kruglanski, \& van der Bles, 2012; Pierro et al., 2008, 2013). This manipulation induces participants into a locomotion or assessment motivational state via a reflection task designed to make the relevant motivational system and sensitivities more accessible. In other words, all participants reflect on different meaningful experiences of goal pursuit, but are differentially focused on locomotion versus assessment-relevant memories. Thus, this approach us allows to directly contrast how a locomotion versus assessment motivational state may influence perceptual judgments of movement.

\section{Method}

Participants and Design. This study was run as part of a class project for a statistics class at a small liberal arts college in the United States. 108 individuals volunteered to participate in the study and were randomly assigned to the locomotion or assessment condition. The goal was to collect data from at least 100 participants; sample size was constrained by the need to complete data collection within a short timeframe for the course. Participants were run in quiet locations around campus (library, empty 


\section{LOCOMOTION AND PERCEPTION}

classrooms) and experimenters were blind to condition. Six participants did not follow instructions for the regulatory mode manipulation (e.g., did not complete the prompt, answered questions other than the ones asked, or provided one word responses) and were excluded from the analysis; the pattern remains the same with and without the excluded participants. ${ }^{4}$ The remaining sample included 102 participants (52 females).

Materials and Procedure. Participants first completed a manipulation of regulatory mode (Avnet \& Higgins, 2003). Participants were told that it was a study about "how people recall their behavior over time." Specifically, all participants were told that they would be asked "to recall three different behaviors you have engaged in successfully in the past and to write a brief paragraph (3-5 sentences) describing each instance. These are the kinds of behaviors that you find people doing in everyday life."

In the locomotion condition, participants were asked to respond to the following three prompts: Think back to a time when you acted like a 'doer'; Think back to a time when you finished one project and did not wait long before you started a new one; Think back to a time when you decided to do something and you could not wait to get started. In the assessment condition, participants were asked to respond to these three prompts: Think back to a time when you compared yourself with other people; Think back to a time when you thought about your positive and negative characteristics; Think back to a time when you carefully evaluated the plans that you or someone else was making.

\footnotetext{
${ }^{4}$ Including all participants, the effect was marginally significant, $D=.26,95 \% C I=-.0002, .51, t(106)=1.98$, $p=.05\left(M_{\text {locomotion }}=5.49, S D_{\text {locomotion }=.66 ;} M_{\text {assessment }}=5.23, S D_{\text {assessment }}=.66\right)$
} 
LOCOMOTION AND PERCEPTION

Following the regulatory mode manipulation, the same images used in Study 1 were presented to participants via powerpoint. ${ }^{5}$ Participants completed a movement rating scale with the same items as used in Study 1, but on a more sensitive nine-point scale ranging from 1(not at all) to 9 (a lot). Participants answered some additional questions about the target unrelated to the current study. Participants then completed demographics questions, were thanked, and debriefed.

\section{Results and Discussion}

As in Study 1, to create an index of perceived movement, movement ratings were averaged across all four pictures $(\alpha=65)$. A t-test examining the effect of regulatory mode on perceptions of movement revealed a mean difference, $D=0.27,95 \% C I=0.01$, 0.53 , Cohen's $d=.41, t(100)=2.06, p=.04$. Individuals in the locomotion condition reported higher movement ratings $(M=5.51, S D=.66)$ than individuals in the assessment condition $(M=5.24, S D=.67)$. Replicating the pattern observed in Study 1 with an experimental induction of regulatory mode, Study 2 provided initial evidence for the causal role of locomotion motivation in movement perception: Momentarily increasing locomotion motivation led to increased perceptual judgments of movement.

\section{Study 3}

\footnotetext{
${ }^{5}$ Due to the nature of the class project in which this data was collected, there were two additional images included in this study not included in Study 1a, 1b, or Study 3 (these images are also pictured in Appendix A). Including all images, the pattern of results remains the same, though the effect is not significant, $D=.20$,

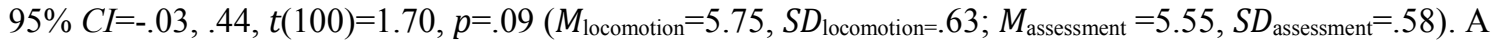
comparison of the movement ratings on these two images relative to the other four revealed that significantly more movement was perceived in these two images, $D=.82,95 \% C I=.65,1.03, t(101)=9.44$, $p<.001\left(M_{\text {Two Images }}=6.20, S D_{\text {Two Images }}=.85 ; M_{\text {Four Images }}=5.38, S D_{\text {Four Images }=.68}\right)$. This suggests that the level of movement in these two pictures may have been less ambiguous, making it more difficult to detect an effect of motivational state when they were included.
} 


\section{LOCOMOTION AND PERCEPTION}

The results of Studies 1 and 2 provide support for the proposal that locomotion motivation, whether measured or manipulated, is associated with increased perceptual judgments of movement. The primary goal of Study 3 was to provide further support with a study that again used an experimental manipulation of regulatory mode. Whereas Study 2 was conducted in the United States, Study 3 was conducted in Canada. Thus, observing the same effect in a different population also provided an opportunity for more confidence about the generalizability of the effect.

In addition, we aimed to extend these findings by examining one potential mechanism for this effect - the motor resonance mechanism discussed earlier. Specifically, in this study, we conducted an initial examination of whether this perceptual judgment effect might be mediated by a locomotion-induced difference in motor/action system activation. As described in the introduction, different theoretical frameworks support this connection. For example, the main tenet of the Theory of Event Coding (Hommel, Müsseler, Aschersleben, \& Prinz, 2001b) is that perceptual outcomes and the action plans that have brought them about are represented in the same 'mental code' and bound as a single mental event. Thus if movement is either chronically or situationally activated, it is possible that representations of related percepts (moving people or objects) are also activated, leading to increased accessibility and greater likelihood of perceiving movement (Bruner, 1957; Eitam \& Higgins, 2010; Higgins, 1996).

Another relevant framework, applied to explain both motor control and judgments of agency, are that of 'forward models'. According to this category of models, prediction of the perceptual consequences of an action is integral to the processes of successfully generating it. As this model is typically applied to motor action (i.e., planned movement), 


\section{LOCOMOTION AND PERCEPTION}

and given recent evidence that locomotion motivation leads to an increase in actual movement (Stadler et al., 2016), it is reasonable to hypothesize that these changes may be associated with an increase in sensitivity to (or weighting of) movement-related perceptual cues when individuals are in a locomotion state.

Consequently, we hypothesized that the increased likelihood for perceptual judgments of movement in a locomotion motivational state may be associated with an increase in the activity of the motor system (indexed by motor responding). If such an association is found, it would highlight the value of considering the ways in which seemingly mysterious effects of 'higher' self-regulatory systems on cognition could be explained by employing extant mechanistic or computational models.

Specifically, in Study 3 we explored the possibility that performance on a go/nogo task (Donders, 1868/1969) might be one way to provide evidence of locomotioninduced motor system activation. The go/no-go task, a cognitive task commonly employed to assess attention and response inhibition, requires participants to quickly initiate responses on "go" trials (e.g., pressing a key as quickly as possible when numbers appear on the screen) while withholding that same behavioral response if certain conditions are met_-"no go" trials (e.g., when the number 3 appears on the screen). Importantly, the task is typically structured so that "no go" trials are relatively infrequent. Thus, the task is designed so that the dominant response is to press a key ("go" trials), a response that must be inhibited on rare trials ("no go" trials). A priori, our motor resonance hypothesis makes one clear prediction : that increased locomotion motivation should be related to better and faster performance on "go" trials and/or worse performance on "no-go trials", given a propensity and desire for movement (i.e., 


\section{LOCOMOTION AND PERCEPTION}

locomotion motivation might always be associated with a "go" response, regardless of trial type).

In sum, Study 3 allowed us to build on the earlier studies in a number of ways. First and foremost, it allowed us to replicate and improve our estimate of the effect of manipulated regulatory mode on movement perception with a different population. It also allowed us to conduct a first test of the motor resonance hypothesis examining if and how the induction of regulatory mode changes performance on a go/no-go task.

\section{Method}

Participants. 124 participants at a large Canadian university completed the study for course credit. Participants were randomly assigned to a locomotion or assessment induction. The goal was to collect data from 50-60 participants per condition. As in Study 2, participants ( $12 \%$ or 15 participants) who did not follow instructions for the regulatory mode induction task were excluded prior to the analyses, leaving a sample of 109 participants (75 females, 1 participant who did not indicate gender). The pattern remains the same with the excluded participants though it was not statistically significant. ${ }^{6}$

Materials and Procedure. Participants first completed the same regulatory mode induction employed in Study 2. They then completed a go/no-go task, also known as a sustained attention to response test. The task was closely modelled after that used in prior studies with a random presentation of "go" and "no go" trials (O'Connell et al., 2009). Participants were told that digits from 1 to 9 would be presented on the computer screen and that, as soon as a digit appeared, their job was to press the left mouse button unless

\footnotetext{
${ }^{6}$ Including all participants, the effect was not significant, $D=.15,95 \% C I=-.02, .32$, $t(122)=1.75, p=.08\left(M_{\text {locomotion }}=4.41, S D_{\text {locomotion }}=0.53 ; M_{\text {assessment }}=4.26, S D_{\text {assessment }}=0.41\right)$.
} 


\section{LOCOMOTION AND PERCEPTION}

the digit was 3. In that case, they were to withhold a key press. Digits appeared for 250 ms; participants had up to $900 \mathrm{~ms}$ to press a key before the next trial began, but they were encouraged to respond immediately when the digit disappeared. The white digits' font sizes were 20, 24, 28, 32, and 36 in Arial and were presented above a central white fixation cross on a black background, closely following O'Connell et al. (2009). Participants completed 36 practice trials before beginning the experimental task (each digit was presented 4 times). The experimental task was composed of 270 trials ( 240 go trials and 30 no-go trials, each digit repeating 30 times).

Participants then completed the same picture-rating task used in Studies 1a and 1b. After the picture-rating task, participants completed additional questionnaires and pilot tasks not related to the current study.

\section{Results and Discussion}

Movement Perception. Consistent with Study 1 and replicating the effect of experimentally inducing locomotion motivation in Study 2, participants made greater judgments of movement in the locomotion condition than in the assessment condition, $D=.20,95 \% C I=.02, .37$, Cohen's $d=.43, t(107)=2.19, p=.03\left(M_{\text {locomotion }}=4.44, S D=.53\right.$; $\left.M_{\text {assessment }}=4.24, S D=.40\right)$. Employing a different population, Study 3 provides an important replication of a situational induction of locomotion motivation leading to changes in perceptual judgments of movement.

Go/No-Go Performance. We examined the four basic measures produced by the task when assessing the go/no-go task: percentage correct on both go and no-go trials and reaction times for key presses on both go and no-go trials. ${ }^{5}$ We also assessed overall performance (percentage correct across all trials). 


\section{LOCOMOTION AND PERCEPTION}

There was no significant effect of our regulatory mode manipulation on

percentage correct for no-go trials, $D=3 \%, 95 \% C I=-.04, .10, t(105)=.83, p=.41$

$\left(M_{\text {locomotion }}=70 \%, S D=16 \% ; M_{\text {assessment }}=67 \%, S D=21 \%\right)$; reaction times for incorrect key

presses on no-go trials, $D=1.28 \mathrm{~ms}, 95 \% C I=-26.76,24.18, t(102)=.10, p=.92$

$\left(M_{\text {locomotion }}=270.25 \mathrm{~ms}, S D=55.77 \mathrm{~ms} ; M_{\text {assessment }}=271.53 \mathrm{~ms}, S D=74.72 \mathrm{~ms}\right)$; or reaction

times for key presses on go trials, $D=19.22,95 \% C I=-47.64,9.22, t(105)=1.34, p=.18$

$\left(M_{\text {locomotion }}=308.01 \mathrm{~ms}, S D=59.81 \mathrm{~ms} ; M_{\text {assessment }}=327.23 \mathrm{~ms}, S D=86.75 \mathrm{~ms}\right)$. There was

also no significant effect of our regulatory mode manipulation on overall performance,

$D=4 \%, 95 \% C I=-.09, .008, t(105)=1.65, p=.10\left(M_{\text {locomotion }}=70.74 \%, S D=12.38 \%\right.$;

$\left.M_{\text {assessment }}=74.74 \%, S D=12.67 \%\right)$. Reaction time analyses were conducted on both the

raw and log-transformed data; there was no change in the pattern or statistical

significance of the results. However, and contrary to our hypothesis, locomotion-induced

participants performed marginally worse on "go" trials relative to participants in the

assessment condition, $D=5 \%, 95 \% C I=-.01, .002$, Cohen's $d=.38, t(105)=1.92, p=.058$,

$\left(M_{\text {locomotion }}=71 \%, S D=13 \% ; M_{\text {assessment }}=76 \%, S D=13 \%\right)$.

Given the a priori hypothesis that locomotion-induced participants should perform better on the "go" trials, we conducted a supplementary Bayesian analysis to further evaluate these results. This analysis resulted in a Bayes factor of .28 , reflecting substantial support for the null hypothesis that there was no difference between the groups. ${ }^{7}$ Thus, we believe the go/no-go results provide no strong evidence for motor

\footnotetext{
${ }^{7}$ To perform the analysis we estimated the probable effect size (when locomotion is manipulated) by using the effect of the manipulation on judgments of movement. That effect is $\sim 3 \%(.2 / 7)$. Using Dienes' Bayes calculator (http://www.lifesci.sussex.ac.uk/home/Zoltan_Dienes/inference/Bayes.htm) and a half normal with a mean of zero and a standard deviation of 3 (the probable prior effect size).
} 


\section{LOCOMOTION AND PERCEPTION}

activation as the mediator of the locomotion effect on perceptual judgment (i.e., against the motor resonance hypothesis).

Post hoc, one may think disrupted performance on the "go" trials may also be consistent with evidence of movement-related concerns within the locomotion system. The nature of the go/no-go task as a whole is likely anathema to individuals in a high locomotion state given that the task is fundamentally about stopping or disrupting movement. But this result will need to be replicated and explored further. ${ }^{8}$ However, the Bayesian analysis suggests that the chances of replication are not high.

\section{General Discussion}

Five studies consistently showed that locomotion motivation is associated with increased perceptual judgments of movement. Whether measured or manipulated, locomotion motivation was related to reporting more movement in static images relative to individuals low in locomotion motivation (Studies $1 \mathrm{a}$ and $1 \mathrm{~b}$, replication noted in Footnote 3) or to individuals induced into an assessment motivational state (Studies 2 and 3). These findings add to the existing literature on how motivation influences perceptual representations by providing evidence that motivation, at a very broad level, can affect perceptual judgments. Previous research has shown that a concrete, active goal can influence perceptions that are in the service of that goal (e.g., Balcetis \& Dunning, 2010, 2006). The current studies suggest that even in the absence of specific goal facilitation, a

\footnotetext{
8 Post hoc, we also examined whether any of the performance indices on the go/no-go task were correlated with perceptual judgments of movement in the picture rating task. Percentage correct for "go" trials was negatively correlated with perceptual judgments of movement $(r=-.30, p=.002)$. Percentage correct for "no go" trials was also marginally negatively correlated with perceptual judgments of movement $(r=-.18$, $p=.06)$. There was a significant negative correlation between reaction times on "go" trials and perceptual judgments of movement $(r=-.20, \mathrm{p}=.04)$. This seems like a real reduction in performance as there was no significant correlation between reaction times for incorrect "no go" trials and perceptual judgments $(r=.02$, $p=.87$ ).
} 


\section{LOCOMOTION AND PERCEPTION}

general motivation can shape perceptual judgments. When signals are ambiguous, one's motivational orientation may provide (at least some of) the perceptual lens through which they are viewed.

The current studies provide evidence of locomotion motivation affecting perceptual judgments in a context in which it is difficult to argue that the effects are due to some type of reporting bias. While there may be instances in which locomotors could be biased to report greater movement than they actually perceived, the task used in all studies was designed and presented so that it clearly communicated to participants that there were no correct answers for the image ratings. Furthermore, there were no consequences (positive or negative) for reporting more or less movement. Finally, and potentially of key importance, the purpose and hypotheses of the studies were not transparent for participants. In Study 1a the relevant predictors were measured well before (weeks) the presentation of the target images and were embedded in a long sequence of other measurements and tasks. In Studies 2 and 3 the experimental induction of locomotion and the presentation of the target occurred in the same session, but the induction itself did not refer to perception or to concepts of movement or motion in any way. Thus, it is doubtful that such a demand would be communicated to the participants.

The present work expands research on motivated perceptual representations by illustrating a connection between a general motivational orientation and perceptual judgments. We believe that it also lays the foundation for future work to explore whether this relation supports greater goal engagement. As also noted in the introduction, research has shown that locomotors persist well through challenges (Kruglanski et al., 2000), tend to be intrinsically motivated (Pierro, Kruglanski, \& Higgins, 2006), have less regret about 


\section{LOCOMOTION AND PERCEPTION}

past experiences and actions (Pierro et al., 2008), and are less prone to procrastination

(Pierro et al., 2011). The current work raises the intriguing question of whether increased perceptual judgments related to the locomotion motivational system might support more effective self-regulation.

As one example, if increased locomotion is related to perceptions of the world as more dynamic (i.e., moving and changing), might this match or regulatory fit between goal orientation and environment facilitate general perceptions that the world "feels right" (Higgins, 2000), thereby strengthening engagement and performance (Higgins, 2006). Additionally, increased perceptions of movement may also relate to perceptions that the past is further away, which would reduce regret, or that the future is closer, which would reduce procrastination (delaying action). Such possibilities will be exciting to examine in future research.

It is also possible that the self-relevance of the perceptual judgment could enhance the effect of locomotion motivation on perceptual judgments of movement. When pursuing goals, individuals not only regulate and monitor the distance between their current state and the desired end-state, but the rate or velocity at which the discrepancy is being reduced (Carver \& Scheier, 1990, 1998). While past research would suggest that locomotors ( $v s$. assessors) would be highly sensitive to velocity, the present research also leads to the speculation that locomotion motivation could be related to judgments of velocity. This, in turn, could produce stronger negative affective reactions to insufficient velocity or rate of progress (see Carver \& Scheier, 1990, for a discussion of negative affective reactions to insufficient rate of progress). Future research examining whether 


\section{LOCOMOTION AND PERCEPTION}

and if the self-relevance of the judgment affects the link between locomotion and perceptual judgments of movement will be another interesting direction to pursue.

\section{Concluding Thoughts}

This work represents an initial foray into the relation between locomotion motivation and perceptual judgments of movement, coming at a time when there is significant debate about the relation between motivation and perception (Firestone \& Scholl, 2015; Rolfs \& Dambacher, in press; Vinson et al., in press). While Study 3 did not support the motor resonance hypothesis, suggesting that the locomotion-induced change in movement perceptual judgments is unlikely to be mediated by motor activation, there are many other mechanisms left to test, mechanisms that are generally linked to the notion that motivational relevance could increase accessibility. Individuals in a locomotion motivational state may have greater accessibility for both movement and movement-related stimuli (Eitam \& Higgins, 2010), may set a lower threshold for its perception, or may be more likely to simulate movement when they see it (Buccino et al., 2001; Casile \& Giese, 2006; Knoblich \& Flach, 2001). Exploring these other mechanisms will be important in future research.

In addition to adding to a broader literature on motivation and perceptual representations, the current studies suggest some interesting implications regarding the nature of locomotion motivation. Certain types of situations and performance contexts could be a particularly good fit for locomotors or a particularly poor fit. Locomotors may excel in contexts that require detection of low levels of movement (e.g., surveillance tasks), but may also be particularly vulnerable to false alarms in such settings. Further 
LOCOMOTION AND PERCEPTION

investigations will provide additional insight into how fundamental motivations, like locomotion concerns, can shape the lens through which individuals view their world. 
LOCOMOTION AND PERCEPTION

\section{References}

Allport, G. W., \& Pettigrew, T. F. (1957). Cultural influence on the perception of movement: The trapezoidal illusion among Zulus. The Journal of Abnormal and Social Psychology, 55(1), 104-113.

Appelt, K. C., Zou, X., \& Higgins, E. T. (2010). Feeling right or being right: When strong assessment yields strong correction. Motivation and Emotion, 34(3), 316324.

Avnet, T., \& Higgins, E. T. (2003). Locomotion, assessment, and regulatory fit: Value transfer from "how" to "what." Journal of Experimental Social Psychology, 39, $525-530$.

Balcetis, E., \& Dunning, D. (2010). Wishful seeing: More desired objects are seen as closer. Psychological Science, 21(1), 147-152.

Balcetis, E., Dunning, D. , \& Granot, Y. (2012). Subjective value determines initial dominance in binocular rivalry. Journal of Experimental Social Psychology, $48(1), 122-129$.

Balcetis, E., \& Dunning, D. (2006). See what you want to see: Motivational influences on visual perception. Journal of Personality and Social Psychology, 91(4), 612-625.

Balcetis, E., \& Dunning, D. (2007). Cognitive dissonance and the perception of natural environments. Psychological Science, 18(10), 917-921.

Bruner, J. S. (1957). On perceptual readiness. Psychological Review, 64(2), 123-152. https://doi.org/10.1037/h0043805

Bruner, J. S., \& Postman, L. (1949). Perception, cognition, and behavior. Journal of Personality, 18, 14-31. 


\section{LOCOMOTION AND PERCEPTION}

Buccino, G., Binkofski, F., R, G., Fadiga, L., Fogassi, L., Gallese, V., ... -J, H. (2001). Action observation activates premotor and parietal areas in a somatotopic manner: An fMRI study. European Journal of Neuroscience, 13(2), 400-404.

Carver, C. S., \& Scheier, M. F. (1990). Origins and functions of positive and negative affect: A control-process view. Psychological Review, 97(1), 19-35.

Carver, C. S., \& Scheier, M. F. (1998). On the self-regulation of behavior. New York: Cambridge University Press.

Casile, A., \& Giese, M. A. (2006). Nonvisual motor training influences biological motion perception. Current Biology: $C B, 16(1), 69-74$.

di Pellegrino, G., Fadiga, L., Fogassi, L., Gallese, V., \& Rizzolatti, G. (1992).

Understanding motor events: a neurophysiological study. Experimental Brain Research,91(1), 176-180.

Dienes, Z. (2008). Understanding psychology as a science: An introduction to scientific and statistical inference. London: Palgrave Macmillan.

Donders, F. C. (1969). On the speed of mental processes. Acta Psychologica, 30, 412431.

Eitam, B., \& Higgins, E. T. (2010). Motivation in mental accessibility: Relevance of a Representation (ROAR) as a new framework. Social and Personality Psychology Compass, 4(10), 951-967.

Eitam, B., Yeshurun, Y., \& Hassan, K. (2013). Blinded by irrelevance: Pure irrelevance induced "blindness." Journal of Experimental Psychology: Human Perception and Performance, 39(3), 611-615. 


\section{LOCOMOTION AND PERCEPTION}

Firestone, C., \& Scholl, B. J. (2015). Cognition does not affect perception: Evaluating the evidence for "top-down" effects. Behavioral and Brain Sciences.

Gallese, V., Fadiga, L., Fogassi, L., \& Rizzolatti, G. (1996). Action recognition in the premotor cortex. Brain, 119(2), 593-609.

Gibson, J. J. (1954). The visual perception of objective motion and subjective movement. Psychological Review, 61(5), 304-314.

Gollwitzer, P. M. (1990). Action phases and mind-sets. Handbook of Motivation and Cognition: Foundations of Social Behavior, 2, 53-92.

Higgins, E. T. (1996). Knowledge activation: Accessibility, applicability, and salience. In E. T. Higgins \& A. W. Kruglanski (Eds.), Social psychology: Handbook of basic principles (pp. 133-168). New York: Guilford Press.

Higgins, E. T. (2000). Making a good decision: Value from fit. American Psychologist, $55(11), 1217-1230$.

Higgins, E. T. (2006). Value from hedonic experience and engagement. Psychological Review, 113(3), 439-460.

Higgins, E. T., King, G. A., \& Mavin, G. H. (1982). Individual construct accessibility and subjective impressions and recall. Journal of Personality and Social Psychology, $43(1), 35-47$.

Higgins, E. T., Kruglanski, A. W., \& Pierro, A. (2003). Regulatory Mode: Locomotion and Assessment as Distinct Orientations. Advances in Experimental Social Psychology, Vol. 35., 293-344.

Higgins, E. T., \& Scholer, A. A. (2008). When is personality revealed?: A motivated cognition approach. In O.P. John, R.W. Robins, \& L.A. Pervin, (Eds.), Handbook of 


\section{LOCOMOTION AND PERCEPTION}

Personality: Theory and Research (Third edition). (pp. 182-207). New York: Guilford Press.

Hommel, B. (2009). Action control according to TEC (theory of event coding). Psychological Research, 73(4), 512-526.

Hommel, B., Müsseler, J., Aschersleben, G., \& Prinz, W. (2001a). Codes and their vicissitudes. Behavioral and Brain Sciences, 24(5), 910-926.

Hommel, B., Müsseler, J., Aschersleben, G., \& Prinz, W. (2001b). The Theory of Event Coding (TEC): A framework for perception and action planning. Behavioral and Brain Sciences, 24(5), 849-937.

Kelly, G. A. (1955). The psychology of personal constructs. Vol. 1. A theory of personality. Vol. 2. Clinical diagnosis and psychotherapy (Vol. xxviii). Oxford, England: W. W. Norton.

Knoblich, G., \& Flach, R. (2001). Predicting the effects of actions: Interactions of perception and action. Psychological Science, 12(6), 467-472.

Kruglanski, A. W., Thompson, E. P., Higgins, E. T., Atash, M. N., Pierro, A., Shah, J. Y., \& Spiegel, S. (2000). To "do the right thing" or to "just do it": Locomotion and assessment as distinct self-regulatory imperatives. Journal of Personality and Social Psychology, 79(5), 793-815.

Love, J., Selker, R., Marsman, M., Jamil, T., Dropmann, D., Verhagen, A. J., ... Wagenmakers, E. J. (2015). JASP (Version 0.7.5).

Mannetti, L., Giacomantonio, M., Higgins, E. T., Pierro, A., \& Kruglanski, A. W. (2010). Tailoring visual images to fit: Value creation in persuasive messages. European Journal of Social Psychology, 40(2), 206-215. 


\section{LOCOMOTION AND PERCEPTION}

Mannetti, L., Leder, S., Insalata, L., Pierro, A., Higgins, E. T., \& Kruglanski, A. (2009). Priming the ant or the grasshopper in people's mind: How regulatory mode affects inter-temporal choices. European Journal of Social Psychology, 39(6), 11201125.

Mark, I., \& Eitam, B. (2016). Task relevance modulates automatic imitation.

\section{Unpublished Manuscript.}

Masuda, T., \& Nisbett, R. E. (2001). Attending holistically versus analytically: Comparing the context sensitivity of Japanese and Americans. Journal of Personality and Social Psychology, 81(5), 922-934.

McClelland, D. C., \& Atkinson, J. W. (1948). The projective expression of needs: I. The effect of different intensities of the hunger drive on perception. The Journal of Psychology: Interdisciplinary and Applied, 25, 205-222.

Miller, G. A., Galanter, E., \& Pribram, K. H. (1960). Plans and the structure of behavior. New York: Henry Holt and Co.

Morey, R. D., \& Rouder, J. N. (2015). BayesFactor (Version 0.9.11-3).

O’Connell, R. G., Dockree, P. M., Bellgrove, M. A., Turin, A., Ward, S., Foxe, J. J., \& Robertson, I. H. (2009). Two types of action error: Electrophysiological evidence for separable inhibitory and sustained attention neural mechanisms producing error on go/no-go task. Journal of Cognitive Neuroscience, 21(1), 93-104.

Oppenheimer, D. M., Meyvis, T., \& Davidenko, N. (2009). Instructional manipulation checks: Detecting satisficing to increase statistical power. Journal of Experimental Social Psychology, 45(4), 867-872. 


\section{LOCOMOTION AND PERCEPTION}

Orehek, E., Mauro, R., Kruglanski, A. W., \& van der Bles, A. M. (2012). Prioritizing association strength versus value: The influence of self-regulatory modes on means evaluation in single goal and multigoal contexts. Journal of Personality and Social Psychology, 102(1), 22-31.

Orgs, G., Dovern, A., Hagura, N., Haggard, P., Fink, G. R., \& Weiss, P. H. (2016). Constructing Visual Perception of Body Movement with the Motor Cortex. Cerebral Cortex, 26(1), 440-449.

Pierro, A., Giacomantonio, M., Pica, G., Kruglanski, A. W., \& Higgins, E. T. (2011). On the psychology of time in action: Regulatory mode orientations and procrastination. Journal of Personality and Social Psychology, 101(6), 13171331.

Pierro, A., Giacomantonio, M., Pica, G., Mannetti, L., Kruglanski, A. W., \& Tory Higgins, E. (2013). When comparative ads are more effective: Fit with audience's regulatory mode. Journal of Economic Psychology, 38, 90-103.

Pierro, A., Kruglanski, A. W., \& Higgins, E. T. (2006). Regulatory Mode and the Joys of Doing: Effects of "Locomotion" and "Assessment” on Intrinsic and Extrinsic Task-Motivation. European Journal of Personality, 20(5), 355-375.

Pierro, A., Leder, S., Mannetti, L., Higgins, E. T., Kruglanski, A. W., \& Aiello, A. (2008). Regulatory mode effects on counterfactual thinking and regret. Journal of Experimental Social Psychology, 44(2), 321-329.

Riccio, M., Cole, S., \& Balcetis, E. (2013). Seeing the expected, the desired, and the feared: Influences on perceptual interpretation and directed attention. Social and Personality Psychology Compass, 7(6), 401-414. 


\section{LOCOMOTION AND PERCEPTION}

Rolfs, M., \& Dambacher, M. (in press). What draws the line between perception and cognition? Behavioral and Brain Sciences.

Rouder, J. N., Morey, R. D., Speckman, P. L., \& Province, J. M. (2012). Default bayes factors for ANOVA designs. Journal of Mathematical Psychology, 56, 356-374.

Scholer, A. A., \& Higgins, E. T. (2012). Commitment to change from locomotion motivation during deliberation. Motivation and Emotion, 36(2), 114-129.

Stadler, G., Eitam, B., Scholer, A. A., \& Higgins, E. T. (2016). A preference for change: Regulatory mode and physical activity in daily life. Unpublished manuscript.

Vinson, D. W., Abney, D. H., Amso, D., Chemero, A., Cutting, J. E., Dale, R., ... Gallagher, S. (in press). Perception, as you make it. Behavioral and Brain Sciences.

Whiteside, T. C. D. (1963). Visula perception of movement: Edridge Green Lecture delivered at the royal college of surgeons of England on 3rd April 1963. Annals of the Royal College of Surgeons of England, 33(5), 267.

Xiao, J. Y., \& Van Bavel, J. J. (2012). See your friends close and your enemies closer: Social identity and identity threat shape the representation of physical distance. Personality and Social Psychology Bulletin, 38(7), 959-972. 
LOCOMOTION AND PERCEPTION

\section{Table 1}

Model Comparison (Study 1b)

\begin{tabular}{lrrrrr}
\hline \multicolumn{1}{c}{ Models } & P(M) & P(M|data) & BF M & BF $\mathbf{~ 1 0}$ & \% error \\
\hline Null model & 0.250 & 0.102 & 0.342 & 1.000 & \\
locomotion & 0.250 & 0.650 & 5.564 & 6.347 & $2.679 \mathrm{e}-6$ \\
assessment & 0.250 & 0.026 & 0.079 & 0.252 & $6.691 \mathrm{e}-8$ \\
locomote + assess & 0.250 & 0.222 & 0.857 & 2.170 & 0.005 \\
\hline
\end{tabular}

Note. Prior probabilities, likelihood and Bayes Factors for three alternative models of locomotion and assessment predicting perceived movement. Only the model that included locomotion received substantial support. 
Appendix A

Images Used in All Studies

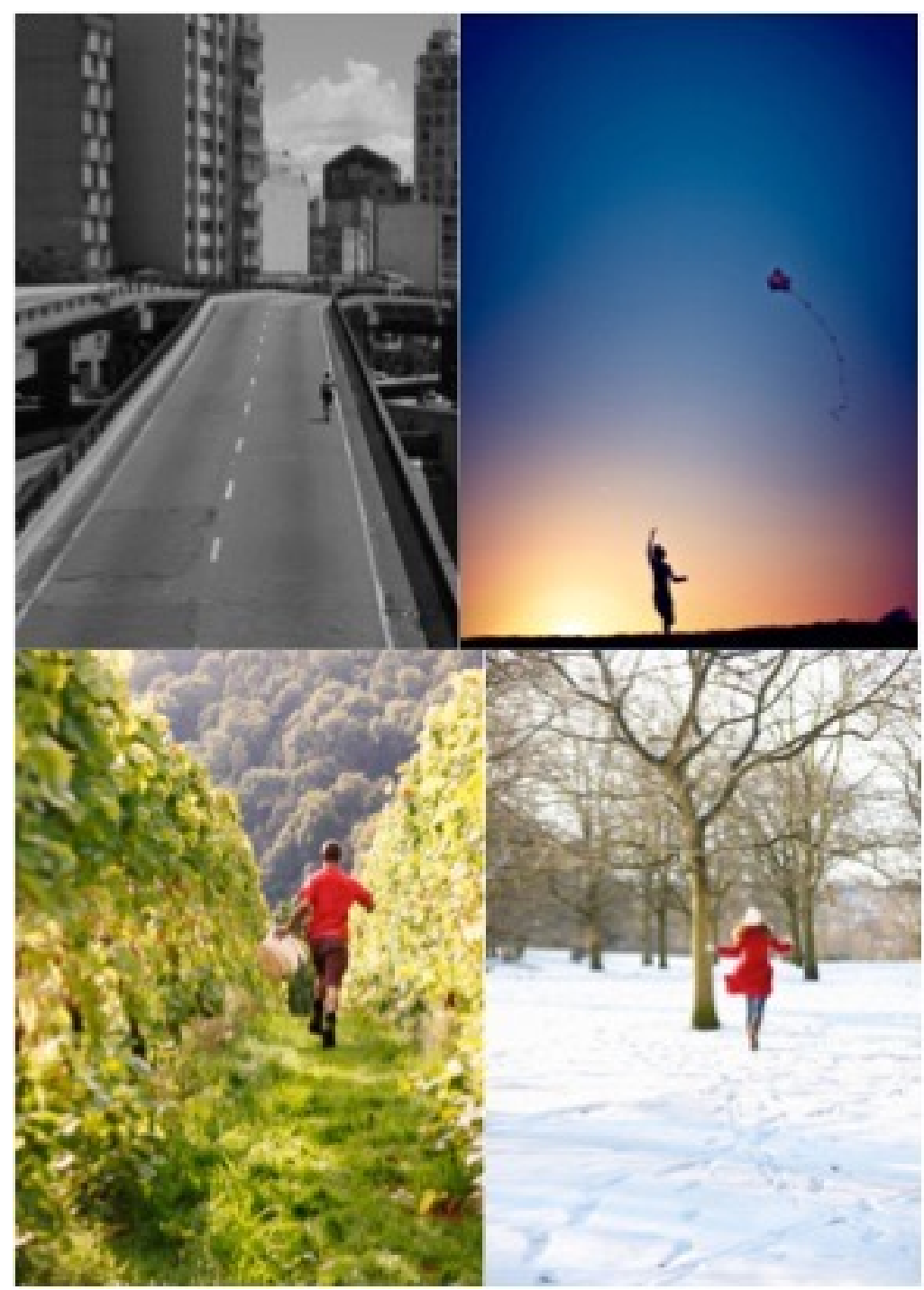

Additional Images Used in Study 2
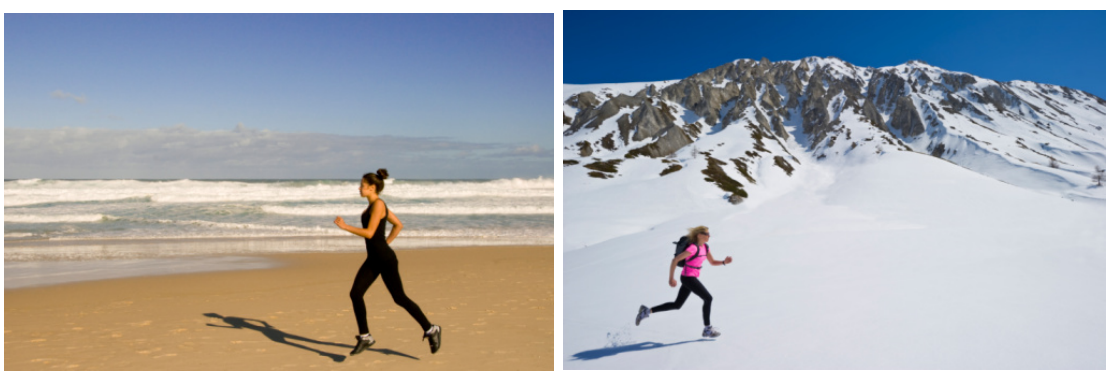